\title{
Nitric Oxide (NO) and Cyclooxygenase-2 (COX-2) Cross-Talk in Co-Cultures of Tumor Spheroids with Normal Cells
}

\author{
Roman Paduch • Martyna Kandefer-Szerszeń
}

Received: 4 November 2010 / Accepted: 9 February 2011 /Published online: 22 February 2011

(C) The Author(s) 2011. This article is published with open access at Springerlink.com

\begin{abstract}
Cyclooxygenases (COX), prostaglandin $\mathrm{E}_{2}\left(\mathrm{PGE}_{2}\right)$ and nitric oxide (NO) are believed to be some of the most important factors related to colon cancer growth and metastasis. In this study, we aimed to investigate the associations between COX-2, $\mathrm{PGE}_{2}$ and $\mathrm{NO}$ in co-cultures of human colon cancer spheroids obtained from different tumor grades with normal human colonic epithelium and myofibroblast monolayers. L-arginine $(2 \mathrm{mM})$, a substrate for nitric oxide synthases (NOS), decreased COX-2 and $\mathrm{PGE}_{2}$ levels, while $\mathrm{N}^{G}$-nitro-L-arginine methyl ester (L-NAME) ( $2 \mathrm{mM})$, a NOS inhibitor, had no influence on COX-2 and $\mathrm{PGE}_{2}$ levels but limited tumor cell motility. NS398 $(75 \mu \mathrm{M})$, a selective COX-2 inhibitor, had no significant influence on $\mathrm{NO}$ level but decreased motility of tumor cells. COX-2, $\mathrm{PGE}_{2}$ and NO levels depended on the tumor grade of the cells, being the highest in Duke's stage III colon carcinoma. Summing up, we showed that addition of L-arginine at doses which did not stimulate NO level caused a significant decrease in COX-2 and $\mathrm{PGE}_{2}$ amounts in co-cultures of colon tumor spheroids with normal epithelial cells and myofibroblasts. Any imbalances in NO level caused by exogenous factors influence COX-2 and $\mathrm{PGE}_{2}$ amounts depending on the kind of cells, their reciprocal interactions
\end{abstract}

R. Paduch $(\bowtie) \cdot$ M. Kandefer-Szerszeń

Department of Virology and Immunology, Institute of Microbiology and Biotechnology,

Maria Curie-Skłodowska University,

Akademicka 19,

20-033 Lublin, Poland

e-mail: rpaduch@poczta.umcs.lublin.pl and the local microenvironmental conditions. The knowledge of these effects may be useful in limiting colon carcinoma progression and invasion.

Keywords Nitric oxide Cyclooxygenase- 2 .

Prostaglandin $\mathrm{E}_{2}$. Colon carcinoma $\cdot$ Co-cultures

\section{Introduction}

Colorectal carcinoma is one of the major causes of cancer patient mortality worldwide. The development, progression and metastasis of this carcinoma are a well-defined series of steps, which among others depend on local nitric oxide (NO) concentration and over-expression of cyclooxygenase (COX) enzymes [1-3].

NO is a short-lived molecule required for physiological functions but also engaged in pathological ones [4]. It can be produced from exogenous sources such as nitrovasodilators or endogenously from L-arginine by NO synthases (NOS) [5]. This molecule exhibits a dual role, stimulating tumor growth and metastasis on the one hand and, on the other hand, inhibiting neoplasia by its antioxidant action, inhibition of angiogenesis, and enhancement of vasodilation, differentiation and apoptosis [6]. These effects are attributed especially to the local NO concentration. At low levels, NO increases tumor growth and development, while higher levels of NO (above optimal concentrations) may express cytotoxic or cytostatic effects [6,7]. The degree of tumor malignancy is also linked to the amount and activity of NOS proteins [8]. It has been shown that the expression 
of NOS may promote metastatic behavior of tumor cells [4]. The level of nitrite and nitrate in serum or culture supernatants can be significantly reduced by application of L-NAME, a competitive inhibitor of NOS. Its activity is based on structural similarity to L-arginine, a substrate for NOS, and competitive inhibition of L-arginine metabolization. It has been shown that L-NAME exerts anti-invasive and anti-metastatic effects on many cancers including colon carcinoma [9].

Some reports also demonstrate a cross-talk between NO and NOS levels and COX expression in cancer cells [10]. COX are essential enzymes which catalyze the conversion of arachidonic acid (AA) to prostaglandins (PGs). Especially the COX-2 isoform is important in carcinogenesis and opens new anticancer therapeutic possibilities [11, 12]. Exposure of various human carcinoma cell lines to COX-2 inhibitors has been shown to induce tumor cell apoptosis in laboratory in vitro tests [13]. It has been shown that the selective COX-2 inhibitor NS398 may in a dose-dependent manner inhibit proliferation and induce death in many carcinomas including colon cancer [14]. COX-2-derived bioactive prostaglandins, especially $\mathrm{PGE}_{2}$, have a direct effect on cancer cells by increasing their motility and metastatic potential [15]. However, $\mathrm{PGE}_{2}$ is one of the main pro-inflammatory factors, which is elevated in colorectal cancers and promotes their development by inducing cell proliferation and inhibiting apoptosis $[16,17]$. Therefore, selective inhibitors of COX-2 may also block $\mathrm{PGE}_{2}$ generation minimizing its colorectaltumor-promoting effects.

Selective inhibition of COX-2 and $\mathrm{PGE}_{2}$ production and influencing NO synthesis in the tumor microenvironment may represent important goals for prevention or therapy of colon cancers. The aim of the present study was to determine the reciprocal relations among $\mathrm{NO}, \mathrm{COX}-2$ and $\mathrm{PGE}_{2}$ in co-cultures of human colon tumor spheroids derived from different tumor grades with normal human colonic epithelium or myofibroblast monolayers in the presence of selective inhibitors of NOS (L-NAME) or COX-2 (NS398) and after the addition of a substrate for NOS (L-arginine).

\section{Materials and Methods}

\section{Cell Culture}

Human colon adenocarcinoma cell lines HT29 (ATCC No. HTB-38) derived from grade I tumor, LS180 (ATCC No. CL-187) from grade II tumor and SW948 (ATCC No. CCL237) from grade III tumor were cultured in RPMI 1640 medium supplemented with $10 \%$ fetal calf serum (FCS) $\left(\mathrm{Gibco}^{\mathrm{TM}}\right.$, Paisley, UK) and antibiotics $(100 \mathrm{U} / \mathrm{ml}$ penicillin and $100 \mu \mathrm{g} / \mathrm{ml}$ streptomycin) (Sigma, St. Louis, MO, USA) at $37^{\circ} \mathrm{C}$ in a humidified atmosphere with $5 \% \mathrm{CO}_{2}$.

Human normal colon myofibroblasts CCD-18Co (ATCC No. CRL-1459) and normal epithelial cells CCD 841 CoTr (ATCC No. CRL-1807) were cultured in RPMI 1640+ DMEM (1:1) medium (Sigma) supplemented with 10\% FCS at $37^{\circ} \mathrm{C}(\mathrm{CCD}-18 \mathrm{Co})$ or $34^{\circ} \mathrm{C}(\mathrm{CCD} 841 \mathrm{CoTr})$ in a $5 \% \mathrm{CO}_{2} / 95 \%$ air atmosphere.

Preparation of Tumor Cell Spheroids

Tumor cell spheroids were prepared by the liquid overlay method, as described previously [18]. In brief, tumor cell suspension $(200 \mu \mathrm{l})$ at a density of $2 \times 10^{5}$ cells $/ \mathrm{ml}$ in RPMI 1640 medium supplemented with $10 \%$ FCS was plated on $1 \%$ agarose-coated 96 -multiwell culture plates $\left(4 \times 10^{4}\right.$ cells/well). After 4 days' incubation at $37^{\circ} \mathrm{C}$ in a humidified atmosphere with $5 \% \mathrm{CO}_{2}$, the cells formed spheroids.

Co-Culture of Tumor Spheroids with a Monolayer of Normal Cells

Tumor spheroids were harvested with glass pipettes from the agarose-coated microplates and transferred into a Petri dish filled with warm RPMI 1640 medium. After 5 min washing, 5 spheroids each were transferred onto confluent monolayers of myofibroblasts and colon epithelial cells in 24-well tissue culture plates in RPMI 1640 medium supplemented with $2 \% \mathrm{FCS}$ and incubated at $37^{\circ} \mathrm{C}$ in a humidified atmosphere with $5 \% \mathrm{CO}_{2}$. Such co-cultures were designed to reflect different stages of tumor metastasis. Parallel experiments with tumor spheroids or normal cell monolayers alone as culture controls were performed. After $24 \mathrm{~h}$ of culture, supernatants and cellular lysates were collected and stored at $-80^{\circ} \mathrm{C}$ until estimation of the amounts of $\mathrm{NO}, \mathrm{PGE}_{2}$ and COX-2.

\section{Exposure of Cells to L-arginine, L-NAME and NS398}

After 24-h incubation of the cells in RPMI 1640 with $10 \%$ FCS, the medium was discarded and fresh RPMI 1640 containing $2 \% \mathrm{FCS}$ and L-arginine ( $2 \mathrm{mM}$ ) (Sigma), L-NAME $(2 \mathrm{mM})$ (Sigma) and NS398 (Sigma) $(75 \mu \mathrm{M})$ was added.

The incubation with the mentioned substances was performed for $24 \mathrm{~h}$. Culture supernatants and cell lysates were collected and stored in $-80^{\circ} \mathrm{C}$ for no longer than 3 months.

\section{Cell Migration Assessment}

Tumor cells were plated at $5 \times 10^{5}$ cells $/ \mathrm{ml}$ on $4 \mathrm{~cm}$ culture dishes (Nunc). After formation of monolayers, culture was scratched with a pipette tip (P300), the medium was 
discarded and the cells were rinsed twice with PBS. Next, a fresh culture medium was applied and the distance of cell migration into the wound area after $24 \mathrm{~h}$ was estimated in the control and the cultures treated with L-arginine, L-NAME and NS398. The plates were stained with the MayGrünwald-Giemsa method. The observation was performed in an Olympus BX51 System Microscope (Olympus Optical CO., LTD, Tokyo, Japan) and the micrographs were prepared using the analySIS® software (Soft Imaging System GmbH, Münster, Germany). The results are a mean distance of migration to 5 selected wound areas taken from 4 micrographs.

\section{ELISA Assay}

The level of human $\mathrm{PGE}_{2}$ was tested immunoenzymatically (ELISA) using a commercially available kit (Cayman Chemical Company, Ann Arbor, MI, USA) according to the manufacturer's instruction. The optical density at $405 \mathrm{~nm}$ was determined using a microplate reader (Molecular Devices Corp., Emax, Menlo Park, CA, USA). The concentrations of $\mathrm{PGE}_{2}$ in the analyzed samples were calculated on the basis of a standard curve. The detection limit was $15 \mathrm{pg} / \mathrm{ml}$.

\section{Nitric Oxide (NO) Measurement}

Nitrate, a stable end product of NO was determined in culture supernatants by a spectrophotometric method based on the Griess reaction. Briefly, $100 \mu \mathrm{l}$ of supernatant was plated in 96-well flat-bottomed plates in triplicate and incubated with $100 \mu \mathrm{l}$ of Griess reagent (1\% sulfanilamide/ $0.1 \% \mathrm{~N}$-(1-naphthyl)ethylenediamine dihydrochloride) (Sigma) in $3 \% \mathrm{H}_{3} \mathrm{PO}_{4}$ (POCH Gliwice, Poland) at room temperature for $10 \mathrm{~min}$. The optical density was measured at $550 \mathrm{~nm}$ using a microplate reader. A standard curve was performed using $0.5-25 \mu \mathrm{M}$ sodium nitrite $\left(\mathrm{NaNO}_{2}\right)$ for calibration.

\section{Immunoblotting}

Total lysate of the treated cells was prepared by adding $150 \mu 1$ of SDS-loading buffer with protease inhibitor cocktail (Sigma) directly to the cells cultured on 24-well plates and detaching them with a cell scraper. The protein concentration was determined using a $\mathrm{BCA}^{\mathrm{TM}}$ Protein Assay Kit (Pierce Biotechnology, Rockford, IL, USA).

The extracts were boiled for $5 \mathrm{~min}$ at $95^{\circ} \mathrm{C}$ and centrifuged at $10.000 \mathrm{rpm}$ for $10 \mathrm{~min}$ at $4^{\circ} \mathrm{C} .15 \mu \mathrm{l}$ of each protein sample was then loaded onto a $9 \%$ SDSpolyacrylamide gel. Following electrophoresis, the proteins were electrotransferred onto Immobilon-P transfer membranes (Millipore, Bedford, MA, USA). The membranes were blocked with 5\% skimmed milk for $1 \mathrm{~h}$ at room temperature and probed with primary goat anti-COX-2 IgG polyclonal antibody (Santa Cruz Biotechnology, Inc.) for

Table 1 Colon tumor cell migration assay. The quantitative results of the measurement of migration distances after colon tumor cells treatment with L-arginine, NS398 and L-NAME

\begin{tabular}{|c|c|c|c|c|}
\hline Cell culture & Inductor & $\begin{array}{l}\text { Cell migration distance as compared } \\
\text { to wounded monolayer }(\mu \mathrm{m})\end{array}$ & $\begin{array}{l}\text { Cell migration distance (\%) as compared to } \\
\text { migration of control, non-treated cells }(100 \%)\end{array}$ & $\begin{array}{l}\% \text { of inhibition of } \\
\text { tumor cell migration }\end{array}$ \\
\hline \multirow[t]{5}{*}{ HT29 } & Wounded monolayer & $742 \pm 11$ & - & - \\
\hline & Non-treated control & $390 \pm 30$ & $100 \%$ & - \\
\hline & L-arginine & $440 \pm 32$ & $85.8 \%$ & $14.2 \%$ \\
\hline & L-NAME & $593 \pm 33$ & $42.3 \%$ & $57.7 \%$ \\
\hline & NS398 & $693 \pm 49$ & $13.9 \%$ & $86.1 \%$ \\
\hline \multirow[t]{5}{*}{ LS180 } & Wounded monolayer & $802 \pm 19$ & - & - \\
\hline & Non-treated control & $385 \pm 26$ & $100 \%$ & - \\
\hline & L-arginine & $497 \pm 32$ & $73.1 \%$ & $26.9 \%$ \\
\hline & L-NAME & $605 \pm 55$ & $47.2 \%$ & $52.8 \%$ \\
\hline & NS398 & $659 \pm 48$ & $34.3 \%$ & $65.7 \%$ \\
\hline \multirow[t]{5}{*}{ SW948 } & Wounded monolayer & $1031 \pm 36$ & - & - \\
\hline & Non-treated control & $623 \pm 57$ & $100 \%$ & - \\
\hline & L-arginine & $689 \pm 65$ & $83.82 \%$ & $16.2 \%$ \\
\hline & L-NAME & $765 \pm 66$ & $65.2 \%$ & $34.8 \%$ \\
\hline & NS398 & $922 \pm 35$ & $26.7 \%$ & $73.3 \%$ \\
\hline
\end{tabular}


2 h. After washing in PBS/1\% Tween 20 (TBS-T), the membranes were labeled with alkaline phosphatase conjugated donkey anti-goat IgG-AP secondary antibodies (Santa Cruz Biotechnology, Inc) for $1 \mathrm{~h}$ at room temperature. After washing with TBS-T, the membranes were visualized with alkaline phosphatase substrates (5bromo-4-chloro-3-indolyphosphate and nitroblue tetrazolium) (BCIP/NBT) (Sigma) in color development buffer (100 mM
Tris with $5 \mathrm{mM} \mathrm{Mg}^{2+}$ at $\mathrm{pH}$ 9.5). As an endogenous control to ensure the same protein loading for each sample, we used $\beta$-actin.

\section{Densitometric Analysis}

Semiquantitative densitometric analysis of the bands was carried out with the Bio-Profil Bio-1D Windows Application
Fig. 1 The effect of L-arginine $(2 \mathrm{mM})$, L-NAME $(2 \mathrm{mM})$ and NS398 $(75 \mu \mathrm{M})$ on the migration capacity of colon tumor HT29 cells. a wounded monolayer, b tumor cell migration after $24 \mathrm{~h}$ in control culture, $\mathbf{c}$ tumor cell migration after 24-h incubation with L-arginine, $\mathbf{d}$ tumor cell migration after 24-h incubation with L-NAME and e tumor cell migration after 24-h incubation with NS398. Bar $=500 \mu \mathrm{m}$

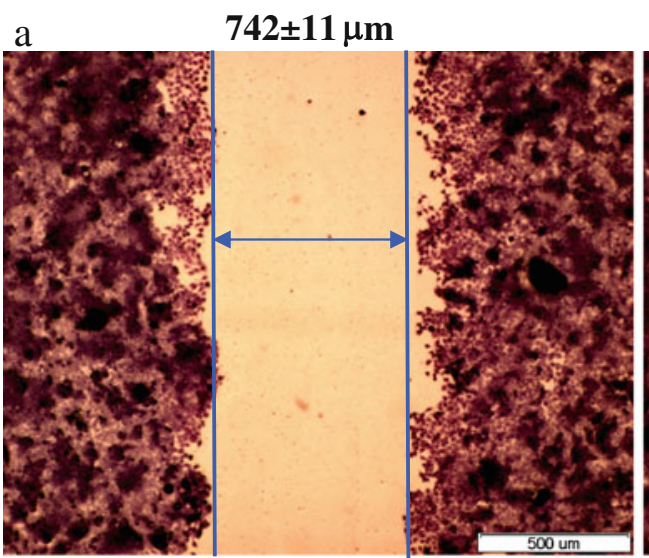

Wounded monolayer

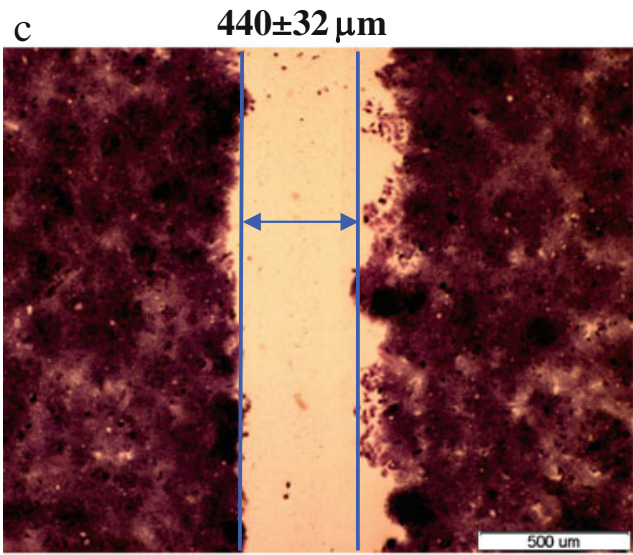

L-arginine addition

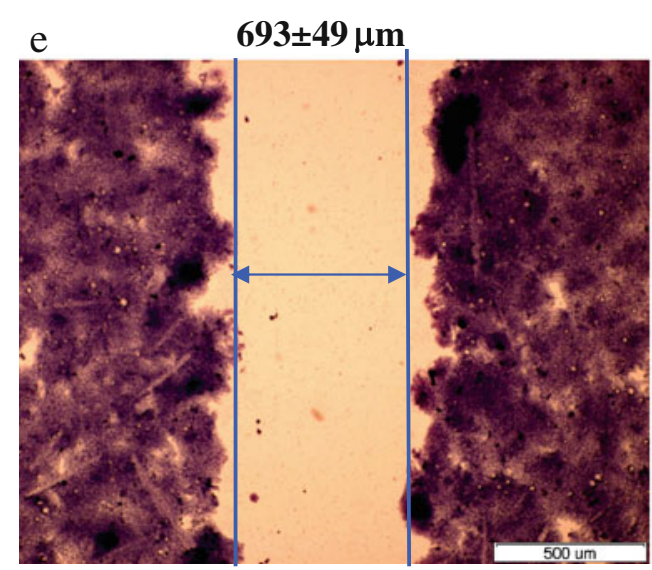

NS398 addition

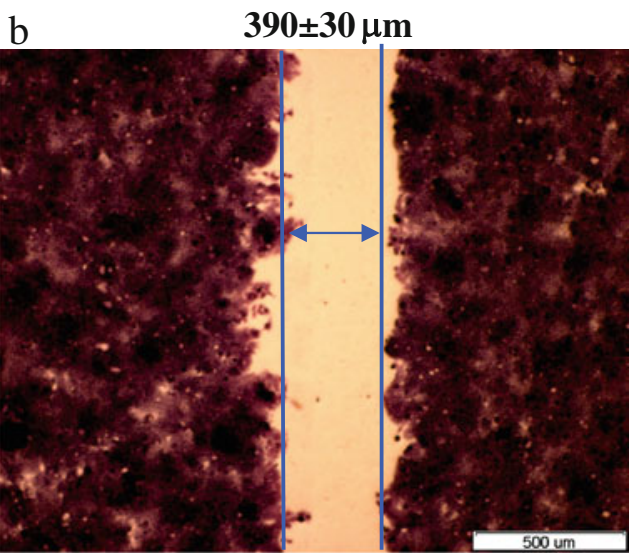

Control

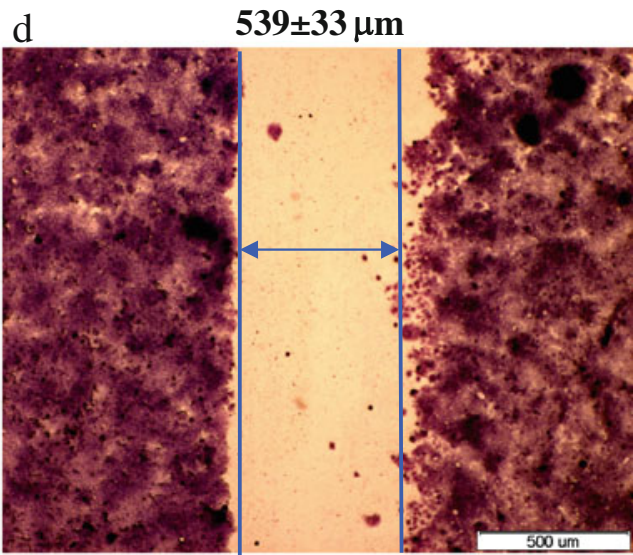

L-NAME addition 
V.99.03 program. The results were presented as density/ volume of the bands.

\section{Statistical Analysis}

Results are presented as means $\pm \mathrm{SD}$ of three independent experiments. The data were analyzed using one-way analysis of variance ANOVA followed by Bonferroni's multiple comparison post-hoc test. Differences of $p \leq 0.05$ were considered significant.
Immunoblots after semiquantitative densitometry were calculated using Student's $t$-test. $p$-values lower than 0.05 were considered significant.

\section{Results}

In the presented study we analyzed the cross-talk among $\mathrm{NO}, \mathrm{COX}-2$ and $\mathrm{PGE}_{2}$ in co-cultures of human colon carcinoma spheroids with human normal colonic epithelium
Fig. 2 a-c Nitric oxide (NO) production in co-cultures of colon carcinoma cell spheroids HT29 (a), LS180 (b) and SW948 (c) with normal colon epithelial cells $(841 \mathrm{CoTr})$ and myofibroblasts $(18 \mathrm{Co})$ during $24 \mathrm{~h}$ of incubation with L-arginine (2 mM), L-NAME $(2 \mathrm{mM})$, and NS398 $(75 \mu \mathrm{M})$. Exposure of cells to L-arginine non-significantly enhanced NO production, while L-NAME significantly inhibited NO secretion as compared to an appropriate sample control. NS398 had no significant influence on NO production. ${ }^{*} p \leq 0.05-$ a co-culture of tumor/normal cells compared to an appropriate monoculture of normal cells. \# $p \leq 0.05-\mathrm{a}$ culture of tumor and/or normal cells after treatment compared to an appropriate non-treated culture

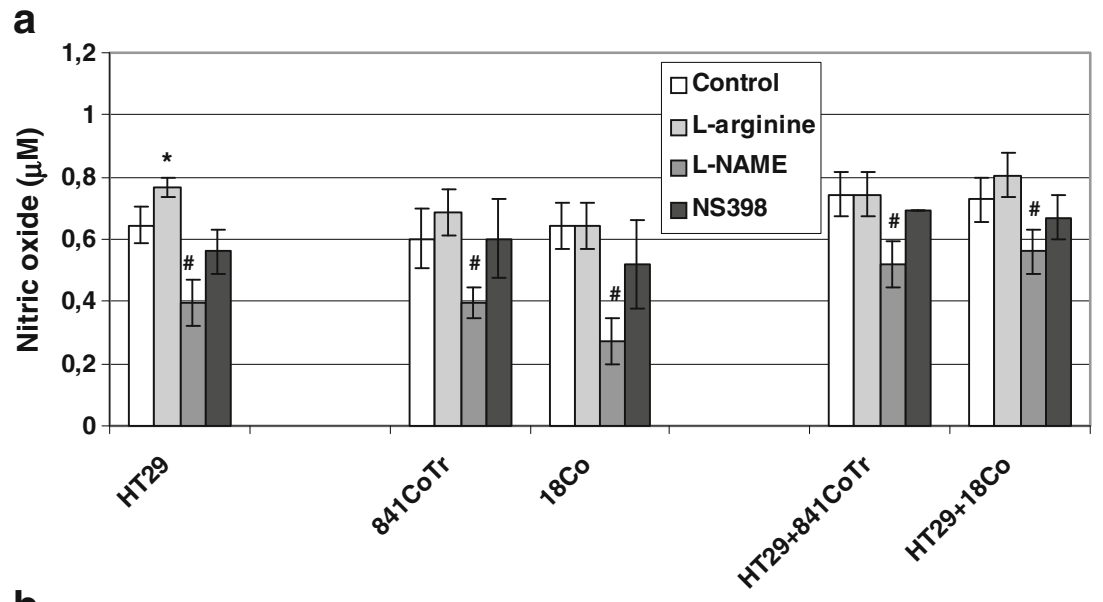

b

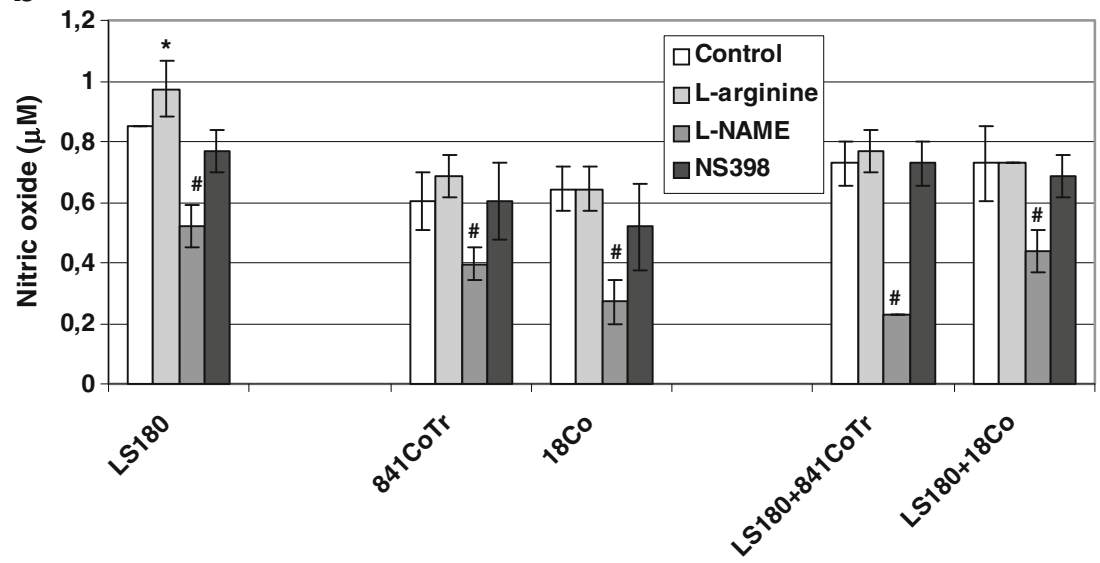

C

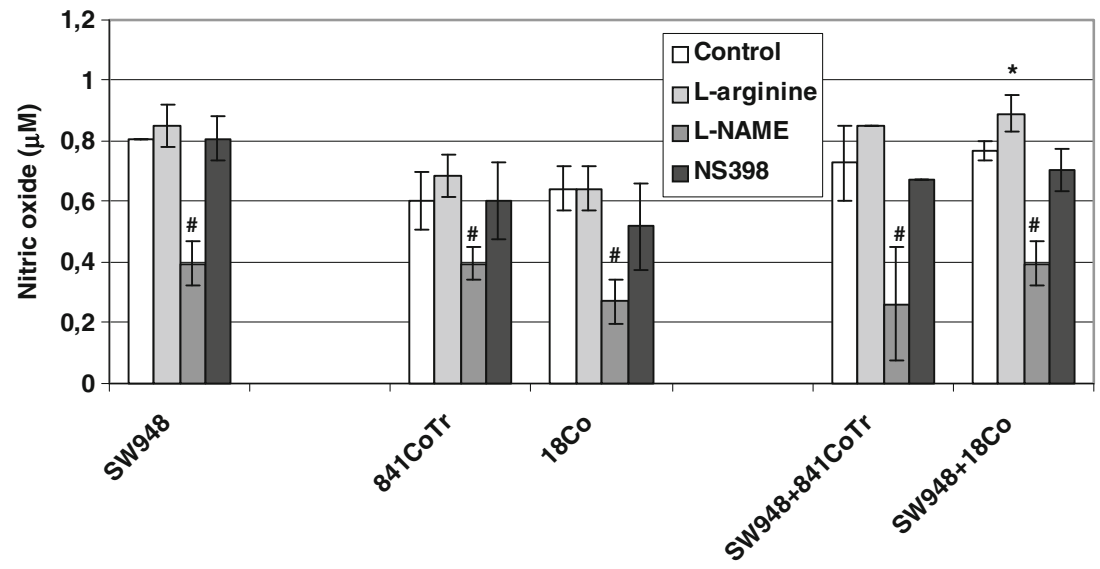


and myofibroblasts mimicking the early steps of colon tumor cell metastasis.

\section{Cell Viability Analysis}

The viability of colon tumor and normal cells was analyzed by the neutral red (NR) uptake assay and the MTT test.

Both tests revealed that L-arginine had no effect on the viability of the tumor and normal cells (data not shown).

\section{Cell Motility Analysis}

Tumor cell migration was analyzed using the wound assay model. The quantitative results of the measurement of migration distances are presented in Table 1 and Fig. 1a-e. We found that treatment of colon tumor cells with NS398 reduced the migration capacities of the cells. L-NAME also blocked the migration of tumor cells but the effect was weaker than that obtained using NS398. Treatment of cells with L-arginine had no significant influence on the motility of colon tumor cells.

\section{NO Production}

Tumor cell spheroids, especially LS180 and SW948, produced higher amounts of NO than an equal number of normal cells cultured as monolayers. Colon epithelial cells produced similar amounts of NO to myofibroblasts. In cocultures, similar concentrations of NO were detected when HT29, LS180 and SW948 cell spheroids were implanted onto normal cell monolayers. Generally, in comparison to tumor cell spheroids (LS180, SW948) cultivated alone, in co-cultures composed of two kinds of cells a decrease in NO production was detected. Exposure of the cells to L-arginine $(2 \mathrm{mM})$ for $24 \mathrm{~h}$ enhanced NO production both in the monoand co-cultures with significant increase in HT29 and LS180 tumor spheroids and SW948 tumor spheroids co-cultured with $18 \mathrm{Co}$ normal cells. On the other hand, L-NAME (2 $\mathrm{mM}$ ) significantly inhibited NO secretion as compared to an appropriate sample control. Finally, NS398 had no significant influence on NO production (Fig. 2a-c).

\section{COX-2 Expression}

COX-2 expression analysis was performed using the immunoblotting method (Fig. 3) followed by densitometry (Fig. $4 \mathrm{a}-\mathrm{c}$ ). We found that in normal colonic epithelium, there was very low or undetectable COX-2 expression. Conversely, colon tumor cells over-expressed COX-2 protein. Additionally, normal stromal myofibroblasts were found to produce COX-2 but in lower amounts than cancer cells. In tumor spheroids co-cultured with normal myofi-
HT29

\section{Myofibroblasts}

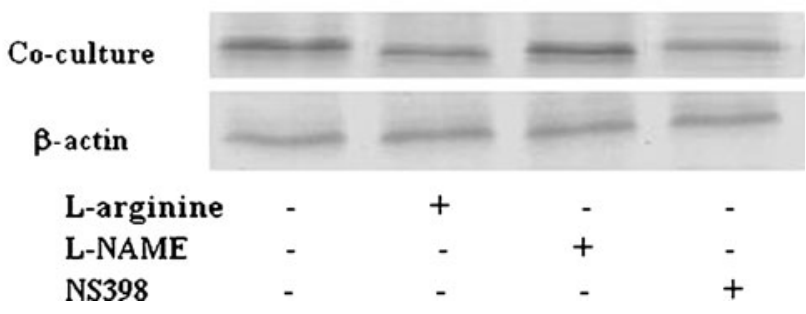

Fig. 3 Western blot analysis of COX-2 after $24 \mathrm{~h}$ of incubation with L-arginine, L-NAME or NS398 in HT29 colon carcinoma cells, myofibroblasts and their co-culture. The increase in band density indicates an increase in protein levels. L-arginine limited COX-2 expression and in tumor cells co-cultured with myofibroblasts the amino acid significantly decreased the enzyme level as compared to a non-treated co-culture. L-NAME non-significantly decreased COX-2 expression as compared to a non-treated co-culture control. NS398 caused a significant inhibition of COX-2 expression

broblasts, COX-2 expression increased above the sum of the enzyme level observed in the respective monocultures. In contrast, in tumor spheroid co-cultures with normal colonic epithelium very low amounts of COX-2 were detected. L-arginine added to normal or tumor cell cultures had no significant influence on COX-2 expression, but in tumor cells co-cultured with myofibroblasts the amino acid significantly decreased the enzyme level as compared to a non-treated co-culture. In mono- and co-cultures treated with L-NAME, non-significant decrease in COX-2 expression was detected as compared to a non-treated co-culture control. The exposure of tumor cells and their co-culture with myofibroblasts to NS398 resulted in a significant inhibition of COX-2 expression.

\section{$\mathrm{PGE}_{2}$ Expression}

The level of $\mathrm{PGE}_{2}$ closely reflected the expression of COX-2 protein. Tumor cells produced significantly higher $\mathrm{PGE}_{2}$ than normal cells. Among the normal cells, myofibroblasts expressed significantly higher $\mathrm{PGE}_{2}$ than colonic epithelium. In co-cultures, the prostaglandin level was lower than the sum of $\mathrm{PGE}_{2}$ produced by the respective monocultures. Addition of L-arginine had no significant influence on $\mathrm{PGE}_{2}$ production either in tumor or normal cells. However, in tumor cell co-cultures with colonic epithelium the decreases of that prostanoid were significant as compared to non-treated controls. L-NAME had no significant influence on $\mathrm{PGE}_{2}$ level, which remained unchanged or slightly decreased in tumor cells, normal cells and their co-cultures as compared to untreated controls. In tumor spheroids, and co-cultures exposed to NS398, a significant inhibition of $\mathrm{PGE}_{2}$ production was 
Fig. 4 a-c Semiquantitative results of a densitometric analysis of the bands of COX-2 protein detected by immunoblotting performed on material obtained from co-cultures of tumor cell spheroids HT29 (a), LS180 (b) and SW948 (c) with normal cells. Only co-cultures of tumor spheroids with colonic epithelium and myofibroblasts were analyzed. Note the lack of COX-2 expression in normal colonic epithelial cells. ${ }^{*} p<0.05$-co-cultures treated with L-arginine, L-NAME or NS398 compared to an untreated co-culture
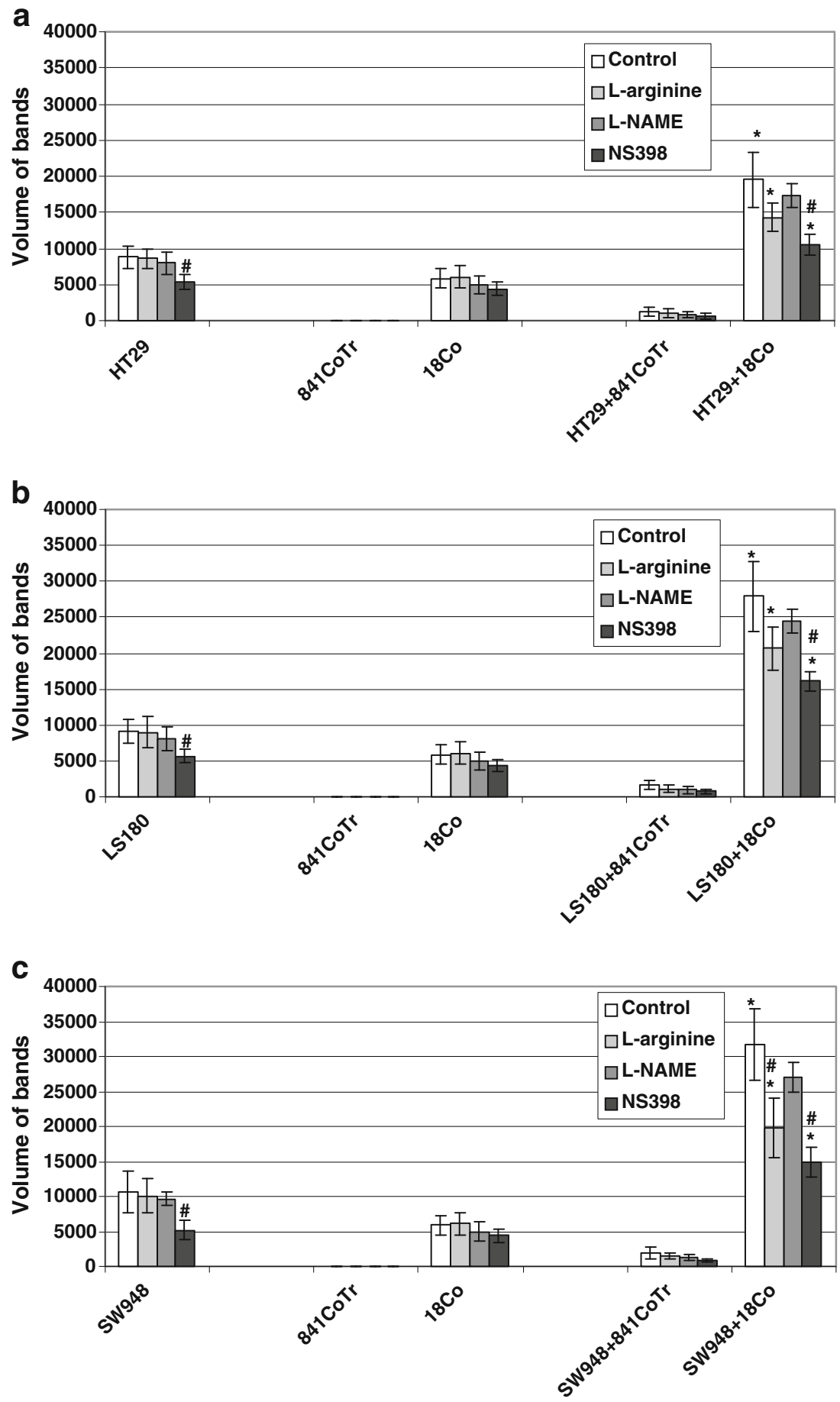

found. In normal cell monolayers inhibition of $\mathrm{PGE}_{2}$ after NS398 addition was non-significant (Fig. 5a-c).

\section{Discussion}

Cyclooxygenases (COX) are essential rate-limiting enzymes catalyzing the conversion of arachidonic acid to prostaglandins (PGs) and other eicosanoids in cells [11, 19]. Three isoforms of COX have been identified: COX-1 and its spliced version COX-3 constitutively expressed in tissues and COX-2, which is regulated by growth factors, cytokines or oncogenes $[20,21]$. It has been clearly shown that COX-2 has tumorpromoting properties. This enzyme has been found to be expressed in approximately $40-50 \%$ of colonic adenomas and to be significantly over-expressed in $80-90 \%$ of colorectal carcinomas $[22,23]$. To date, several mechanisms by which COX-2 contributes to carcinogenesis have been identified. 
Fig. 5 a-c $\mathrm{PGE}_{2}$ production in co-cultures of colon carcinoma cell spheroids HT29 (a), LS180 (b) and SW948 (c) with normal colon epithelial cells and myofibroblasts during $24 \mathrm{~h}$ of incubation with L-arginine, L-NAME or NS398. ELISA test. Tumor cells produced significantly higher $\mathrm{PGE}_{2}$ than normal cells. Myofibroblasts expressed significantly higher $\mathrm{PGE}_{2}$ than colonic epithelium. L-arginine limited $\mathrm{PGE}_{2}$ production in tumor cells, myofibroblasts and their co-cultures. L-NAME had no significant influence on $\mathrm{PGE}_{2}$ level, which remained unchanged or slightly decreased in tumor cells, normal cells and their co-cultures as compared to untreated controls. NS398, inhibited $\mathrm{PGE}_{2}$ production in the tested cells. ${ }^{*} p \leq 0.05-\mathrm{a}$ co-culture of tumor/normal cells compared to an appropriate monoculture of normal cells. \# $p \leq 0.05$ - a culture of tumor and/ or normal cells after treatment compared to an appropriate non-treated culture a

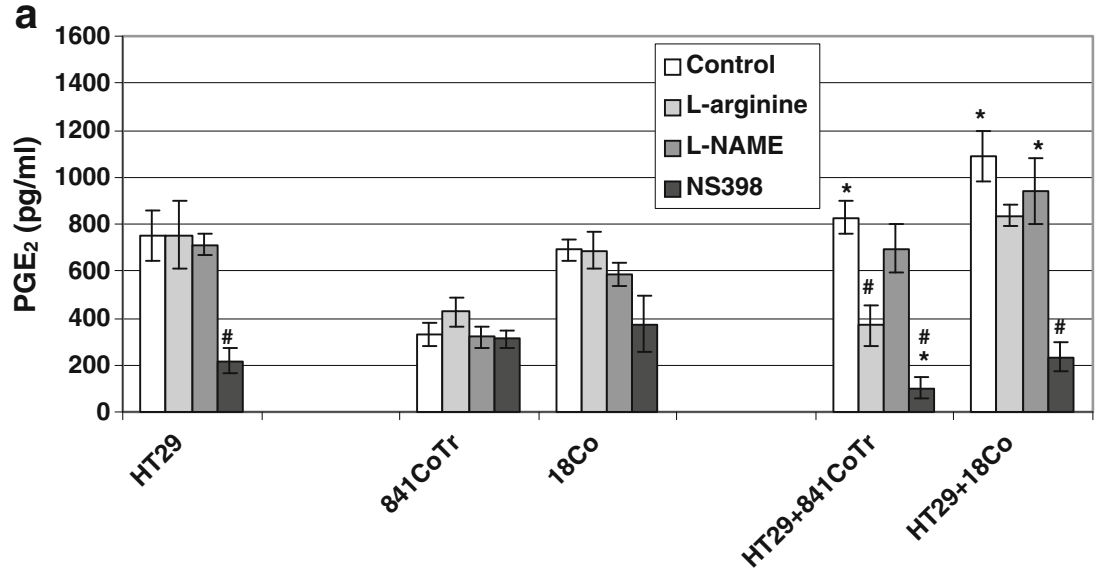

b
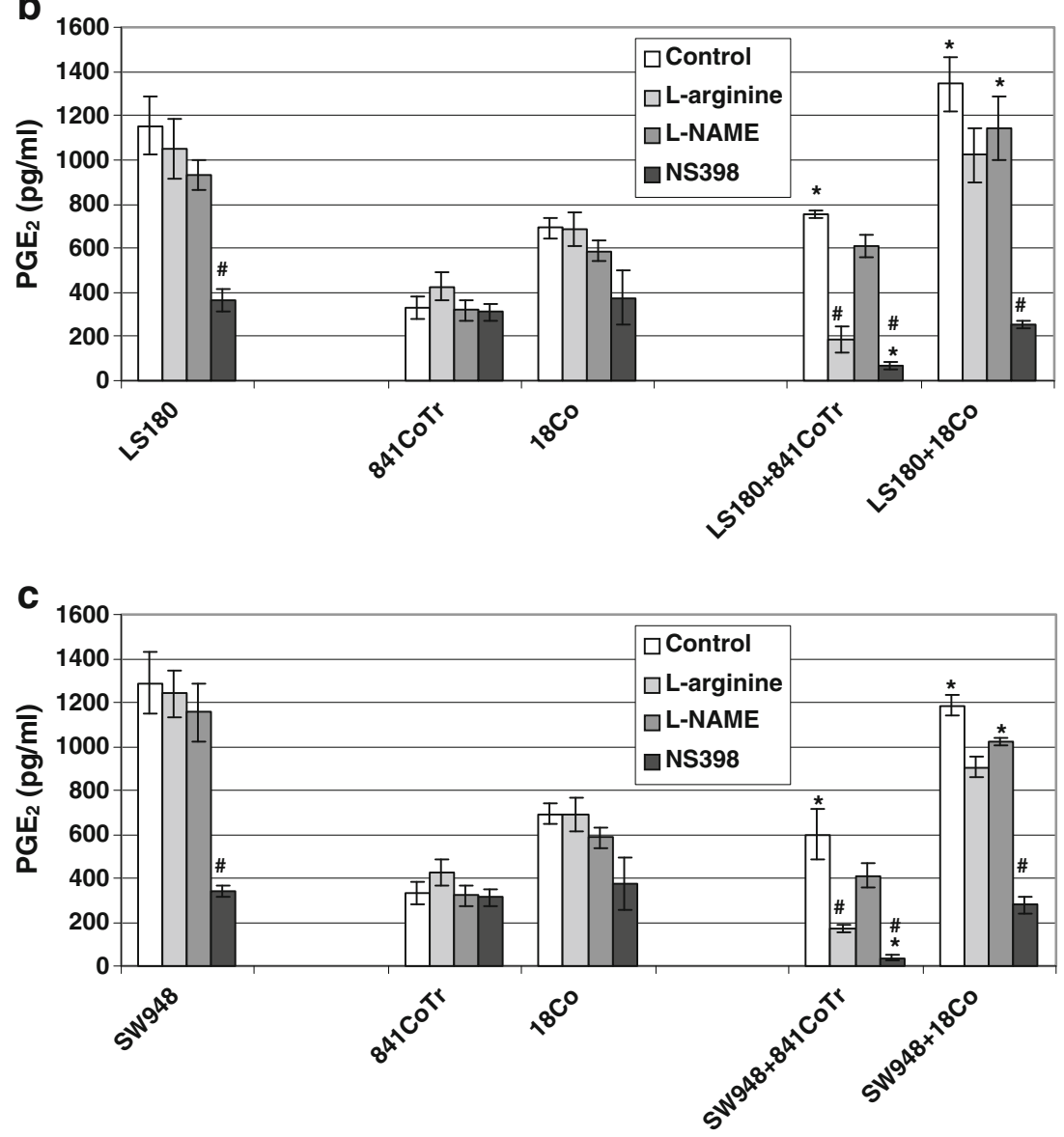

They include inhibition of apoptosis, enhancement of angiogenesis and invasiveness, modulation of inflammation and immunosuppression or conversion of procarcinogens to cancerogenic factors [24]. Finally, COX-2 up-regulation is closely linked with increased production of PGs, especially $\mathrm{PGE}_{2}$, which supports tumor growth by induction of angiogenesis and inhibition of tumor cell apoptosis and exerts immunomodulating effects via, e.g. T-cell response inhibition $[17,25,26]$.
During tumor development and metastasis, a significant role is also attributed to nitric oxide (NO). This molecule is implicated in the regulation of tumorigenesis depending on its local concentration, tumor stage, local microenvironmental conditions or even direct interactions between tumor and stromal cells.

In this study we tried to find a link between $\mathrm{NO}$ and COX-2 and $\mathrm{PGE}_{2}$ levels in co-cultures of colon cancer spheroids prepared from tumor cells isolated from differ- 
ent tumor grades with normal colonic epithelium and myofibroblasts. We analyzed COX-2 and $\mathrm{PGE}_{2}$ levels in the presence of an excess concentration of L-arginine, a substrate for NOS activity and L-NAME, or NS398 as NOS or COX-2 inhibitors, respectively (Fig. 6).

In our study we used single doses of each agent. However, it was intended, because we did not want to analyze the effects depending on different concentrations of inhibitors or L-arginine but the relationship between COX-2, NO and $\mathrm{PGE}_{2}$ in specific culture conditions. We wanted to show that there are changes in specific molecules concentration or whole cells reaction (motility) when other molecules concentration is limited or inhibited their activity. It was only to show that such cross-talk among analyzed molecules exists. The detailed explanation of these observations, obviously, needs further study.

The selection of the dose of each agent was performed multistage. On the basis of the literature we selected a few concentrations. Next, they were tested for their cytotoxicity because in the further experiments we wanted to show often slight and delicate changes in specific molecules amounts. We had to be sure that under any circumstances we did not influence on cells amount or their viability. Thereafter, different concentrations were analyzed on their influence on NO level on normal colon epithelial cells. After that, the most appropriate concentration of inhibitors and L-arginine adapted to our experimental model has been selected.

We had to choose either different concentrations of inhibitors and L-arginine analysis or expand cellular model. The idea of our study was to analyze the relationship among selected parameters and therefore only single doses of inhibitors and L-arginine were used. If different concentrations of these agents and different cellular model combination were analyzed then, as we suppose, the results would be difficult to explain and in consequence difficult to understand.
We showed that COX-2 was over-expressed in colon tumor cells and stromal myofibroblasts but its level was relatively low in normal colon epithelial cells. Some authors have shown that COX-2 expression differs depending on colon tumor grade. Zhang and Sun [11] revealed that frequencies of COX-2 expression were greater in advanced colon tumors (Duke's B-D) than in Duke's A. Similar observations were performed by Williams et al. [27], who showed that higher COX-2 expression was associated with tumors that were advanced and larger in size. In our study we confirmed these clinical observations showing in vitro higher COX-2 and $\mathrm{PGE}_{2}$ amounts in LS180 (grade II) and SW948 (grade III) cells than in the HT29 (grade I) colon cancer culture. In co-cultures, similarly to COX-2, also NO level was comparable to that observed in tumor spheroid monocultures. The lower amounts of NO in co-cultures than in tumor cells cultured alone may be partially due to the general reduction of NO production in tumor cells after their contact with normal cells [28].

NO is produced from L-arginine, a semiessential amino acid which by modulating host immune functions causes variable responses against tumor growth [29, 30]. Larginine, in experimental settings, has been shown to exert anti-tumor effects by reducing tumor size and incidence, and retarding tumor growth and metastasis [31]. Generally, L-arginine may reduce chemically induced colorectal carcinomas influencing host immune system functions [32]. Supplementation with this amino acid also leads to increased NO formation by the oxidative deaminase pathway. In turn, an increased local NO level may induce cytostasis by inhibiting hyperproliferation of tumor cells or cytotoxicity in tumor cells by, e.g. formation of toxic peroxynitrite [33]. Moreover, there is also a cross-talk between products of the NOS and COX pathways. In our study, we showed that L-arginine supplementation slightly increased NO level but had no significant influence on the
Fig. 6 Schematic graph showing reciprocal relations among nitric oxide (NO), nitric oxide synthases (NOS), cyclooxygenase-2 (COX-2), and prostaglandin $\mathrm{E}_{2}\left(\mathrm{PGE}_{2}\right)$

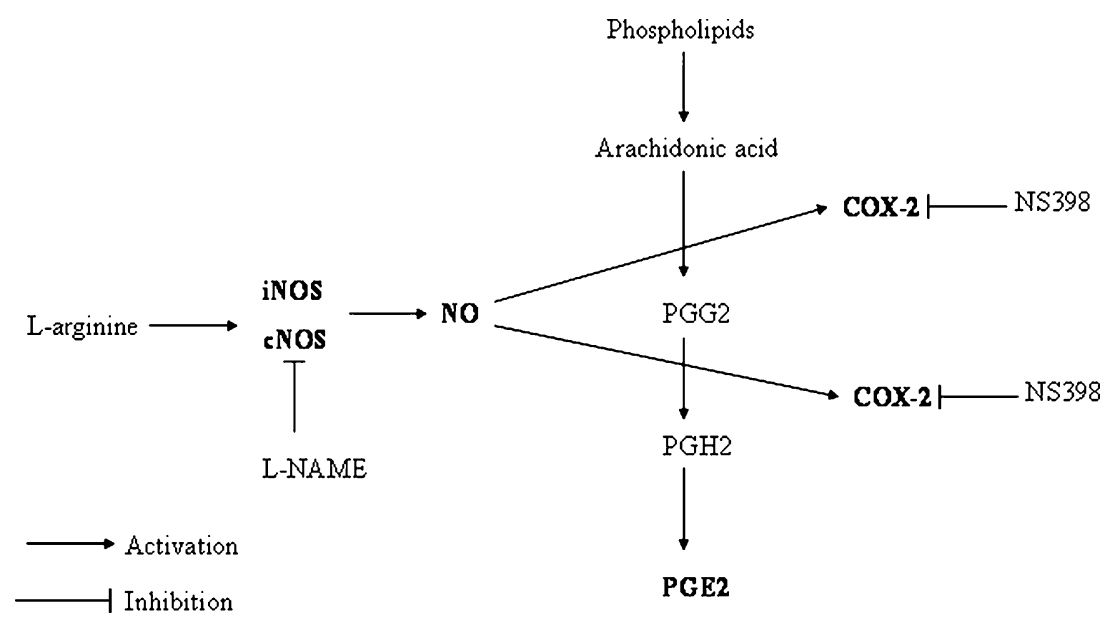


amount of COX-2, and in consequence on $\mathrm{PGE}_{2}$ production in tumor and normal cell monocultures. The interactions between $\mathrm{NO}$ and COX-2 and $\mathrm{PGE}_{2}$ occur at multiple levels and therefore it is difficult to unequivocally speculate about them and give simple answers or solutions. The significant reduction of $\mathrm{PGE}_{2}$ levels by $\mathrm{L}$-arginine was found in cocultures of tumor spheroids with colonic epithelium rather than with myofibroblasts, which may suggest an important role of NO in chemoprevention of tumor-epithelial cell interactions rather than its effect on tumor-stromal development, activity and viability. Our results are in agreement with the findings of Clancy et al. [34] and Ghosh et al. [35], who showed that NO inactivates COX-2 functions through inhibiting its enzymatic activity by reacting with iron in the enzyme's heme group. Moreover, we demonstrated that L-NAME, an inhibitor of NO synthases which decreased NO level and motility of tumor cells in the experiment had a relatively weak effect on COX-2 level. These results are in agreement with the findings of other authors showing a balance and interference with each other's synthesis between NO, COX-2 and $\mathrm{PGE}_{2}[36,37]$. These interactions are important for maintaining homeostasis in normal cells and influence invasiveness in tumors. There exist contradictory reports describing the relationships between NO and COX, showing that blockade of NOS by L-NAME may either increase or decrease COX-2 and $\mathrm{PGE}_{2}$ synthesis [38-40]. We suppose, on the basis of our study, that the NO and COX-2 relationship is closely dependent on the kind of cells that have been used, their direct interactions, the kind of inhibitor applied and the local microenvironmental conditions. These elements together influence COX-2 and $\mathrm{PGE}_{2}$ synthesis after NO imbalance. This hypothesis is confirmed by Ohno et al. [40], who showed that mucosal $\mathrm{PGE}_{2}$ was decreased by SC-560, a COX-2 inhibitor, but not by LNAME. Moreover, other authors have shown that L-NAME reduces $\mathrm{PGE}_{2}$ generation via limitation of COX-2 expression [41]. Therefore, L-NAME may limit the invasion and migration of tumor cells and serve as a cancer prevention factor [10, 42]. Finally, NS398, a specific COX-2 inhibitor, decreased the enzyme and $\mathrm{PGE}_{2}$ levels and tumor cell motility with slight effects on NO production. These results are in agreement with the findings of West et al. [43] and Payá et al. [44], who revealed that NS398 strongly reduced COX-2 and $\mathrm{PGE}_{2}$ levels without affecting NO metabolites and NOS activity. We can only speculate on the mechanism by which COX-2 inhibitor also causes inhibition of the enzyme expression. It may be associated with cell cycle arrest by COX-2 inhibitor what may result in potential decrease in enzyme level. NS398, which acts by inducing a conformational change of COX-2, may also lead to unrecognizing of the protein by specific antibodies. The inhibitor may also cross-influence on molecular pathways and signal transduction connected with enzyme activity and expression. Finally there may be a feedback between COX-2 and $\mathrm{PGE}_{2}$ levels and activity. However, these are only speculations which need experimental confirmation. Moreover, there is strong evidence indicating that specific COX-2 inhibition could down-regulate the antiapoptotic $\mathrm{Bcl}-2$ protein, thus inhibiting proliferation and progression of different carcinomas including colon cancer [14, 45, 46]. At present, there is no uniform explanation of the mechanism of the cross-talks between NO and COX-2 and $\mathrm{PGE}_{2}$ in tumor/normal cell co-cultures. Some evidence indicates that $\mathrm{NO}$ produced from $\mathrm{L}$-arginine contributes to COX-2 and $\mathrm{PGE}_{2}$ activation [47]. However, no answer has been offered to the question of the influence of the $\mathrm{NO}+\mathrm{O}_{2}^{-}$product $\left(\mathrm{ONOO}^{-}\right)$, which is locally produced during direct tumor/normal cell interactions, on COX-2 expression. In our previous work we showed that during direct tumor/normal cell contact $\mathrm{O}_{2}^{-}$anion is overproduced [18]. However, our data obtained so far do not allow to determine whether this is mainly free NO or its reaction product peroxynitric acid, generated through the interaction between tumor cell-derived superoxide anions and NO. In order to distinguish reaction products, additional methods should be applied. Nevertheless, NO as a short-lived and highly reactive molecule will be converted into nitrate, a stable end product of $\mathrm{NO}$, and will react with free oxygen radicals forming reactive oxygen/nitrogen species. The exact kind of molecules formed needs further studies. On the other hand, a large number of experimental results indicate that NO, under certain conditions, downregulates the prostaglandin biosynthetic pathway mainly via COX-2 inhibition [48]. We showed that in tumor or normal cell monocultures NO had no significant influence on COX-2 and $\mathrm{PGE}_{2}$ expression. However, in specific culture conditions when tumor cells directly interacted with normal cells, especially myofibroblasts, the addition of L-arginine resulted in a limitation of COX-2 expression; $\mathrm{PGE}_{2}$ level was decreased when tumor cells were implanted onto normal colon epithelium. Based on these results, we may speculate that $\mathrm{NO}$ and $\mathrm{COX}-2$ and $\mathrm{PGE}_{2}$ cross-talks should be considered in relation to the experimental conditions and the cell culture model used.

In conclusion, we have shown the existence of crosstalks among NO, COX-2 and $\mathrm{PGE}_{2}$. This relationship is rather unidirectional where NO level influences COX-2 and $\mathrm{PGE}_{2}$ levels. Moreover, any imbalances in NO level caused by exogenous factors influence $\mathrm{COX}-2$ and $\mathrm{PGE}_{2}$ amounts depending on the kind of cells, their reciprocal interactions and the local microenvironmental conditions. The knowledge of these effects may be useful in limiting colon carcinoma progression and invasion.

Conflict of Interest The authors declare that they have no conflict of interest. 
Open Access This article is distributed under the terms of the Creative Commons Attribution Noncommercial License which permits any noncommercial use, distribution, and reproduction in any medium, provided the original author(s) and source are credited.

\section{References}

1. Rao ChV, Indranie C, Simi B, Manning PT, Connor JR, Reddy BS (2002) Chemopreventive properties of a selective inducible nitric oxide synthase inhibitor in colon carcinogenesis, administered alone or in combination with celecoxib, a selective cyclooxygenase-2 inhibitor. Cancer Res 62:165-170

2. Tanaka T, Kohno H, Shimada R, Kagami S, Yamaguchi F, Kataoka S, Ariga T, Murakami A, Koshimizu K, Ohigashi H (2000) Prevention of colonic aberrant crypt foci by dietary feeding of garcinol in male F344 rats. Carcinogenesis 21:1183-1189

3. Rao ChV, Kawamori T, Hamid R, Reddy BS (1999) Chemoprevention of colonic aberrant crypt foci by an inducible nitric oxide synthase-selective inhibitor. Carcinogenesis 20:641-644

4. Lala PK, Chakraborty Ch (2001) Role of nitric oxide in carcinogenesis and tumour progression. Lancet Oncol 3:149-156

5. Conners W, Whitebeck C, Chicester P, Legget R, Lin AD-Y, Johnson A, Kogan B, Levin R, Mannikarottu A (2006) L-NAME, a nitric oxide inhibitor, diminishes oxidative damage in urinary bladder partial outlet obstruction. Am J Physiol—Renal Physiol 290:F357-F363

6. Rao ChV (2004) Nitric oxide signalling in colon cancer chemoprevention. Mutat Res 555:107-119

7. Shang Z-J, Li Z-B (2006) In vitro effects of nitric oxide synthase inhibitor L-NAME on oral squamous cell carcinoma: a preliminary study. Int J Oral Maxillofac Surg 35:539-543

8. Gavilanes J, Moro MA, Lizasoain I, Lorenzo P, Pérez A, Leza JC, Alvarez-Vicent JJ (1999) Nitric oxide synthase activity in human squamous cell carcinoma of the head and neck. Laryngoscope 109:148-152

9. Yu L-B, Dong X-S, Sun W-Z, Zhao D-L, Yang Y (2005) Effect of a nitric oxide synthase inhibitor NG-nitro-L-arginine methyl ester on invasion of human colorectal cancer cell line SL-174T. World J Gastroenterol 11:6385-6388

10. Park S-W, Lee S-G, Song S-H, Heo D-S, Park B-J, Lee D-W, Kim $\mathrm{K}-\mathrm{H}$, Sung M-W (2003) The effect of nitric oxide on cyclooxygenase-2 (COX-2) overexpression in head and neck cancer cell lines. Int J Cancer 107:729-738

11. Zhang H, Sun X-F (2002) Overexpression of cyclooxygenase-2 correlates with advanced stages of colorectal cancer. Am J Gastroenterol 97:1037-1041

12. Giercksky K-E (2001) COX-2 inhibition and prevention of cancer. Best Prac Res: Clin Gastroenterol 15:821-833

13. Yoshimatsu K, Yamaguchi K, Otani T, Aizawa M, Ogawa K (2007) Cyclooxygenase II: a molecular target for colorectal cancer prevention and treatment? Ann Cancer Res Therap 15:14-21

14. Huang DS, Shen K-Z, Wei J-F, Liang T-B, Zheng SS, Xie H-Y (2005) Specific COX-2 inhibitor NS398 induces apoptosis in human liver cancer cell line HepG2 through BCL-2. World J Gastroenterol 11:204-207

15. Larkins TL, Nowell M, Singh S, Sanford GL (2006) Inhibition of cyclooxygenase-2 decreases breast cancer cell motility, invasion and matrix metalloproteinase expression. BMC Cancer 6:art. No. 181

16. Tammali R, Ramana KV, Srivastava SK (2007) Aldose reductase regulates TNF- $\alpha$-induced PGE2 production in human colon cancer cells. Cancer Lett 252:299-306

17. Wendum D, Masliah J, Trugnan G, Fléjou J-F (2004) Cyclooxygenase- 2 and its role in colorectal cancer development. Virchows Arch 445:327-333
18. Paduch R, Walter-Croneck A, Zdzisińska B, Szuster-Ciesielska A, Kandefer-Szerszeń M (2005) Role of reactive oxygen species (ROS), metalloproteinase-2 (MMP-2) and interleukin-6 (IL-6) in direct interactions between tumour cell spheroids and endothelial cell monolayer. Cell Biol Int 29:497-505

19. Buecher B, Broquet A, Bouancheau D, Heymann M-F, Jarry A, Denis MG, Bonnet C, Galmiche J-P, Blottière HM (2003) Molecular mechanisms involved in the antiproliferative effect of two COX-2 inhibitors, nimesulide and NS-398, on colorectal cancer cell lines. Dig Liver Dis 35:557-565

20. Bijman MNA, Hermelink CA, van Berkel MPA, Laan AC, Janmaat ML, Peters GJ, Boven E (2008) Interaction between celecoxib and docetaxel or cisplatin in human cell lines of ovarian cancer and colon cancer is independent of COX-2 expression levels. Biochem Pharmacol 75:427-437

21. Tuynman JB, Peppelenbosch MP, Richel DJ (2004) COX-2 inhibition as a tool to treat and prevent colorectal cancer. Crit Rev Oncol Hematol 52:81-101

22. Peek Jr RM (2004) Prevention of colorectal cancer through the use of COX-2 selective inhibitors. Cancer Chemother Pharmacol 54 (Suppl. 1):S50-S56

23. Hasegawa K, Ichikawa W, Fujita $T$, Ohno R, Okusa $T$, Yoshinaga K, Sugihara K (2001) Expression of cyclooxygenase-2 (COX-2) mRNA in human colorectal adenomas. Eur J Cancer 37:1469-1474

24. Dempke W, Rie Ch, Grothey A, Schmoll H-J (2001) Cyclooxygenase-2: a novel target for cancer chemotherapy. J Cancer Res Clin Oncol 127:411-417

25. Sun Q, Liu Q, Zheng Y, Cao X (2008) Rapamycin suppresses TLR-4-triggered IL-6 and $\mathrm{PGE}_{2}$ production of colon cancer cells by inhibiting TLR4 expression and NF- $\kappa \mathrm{B}$ activation. Mol Immunol 45:2929-2936

26. Morioka Y, Ikeda M, Saiga A, Fujii N, Ishimoto Y, Arita H, Hanasaki K (2000) Potential role of group X secretory phospholipase $\mathrm{A}_{2}$ in cyclooxygenase-2-dependent $\mathrm{PGE}_{2}$ formation during colon tumorigenesis. FEBS Lett 487:262-266

27. Williams CS, Luongo C, Radhika A, Zhang T, Lamps LW, Nanney LB, Beauchamp RD, DuBois RN (1996) Elevated cyclooxygenase-2 levels in Min mouse adenomas. Gastroenterol 111:1134-1140

28. Hsi LC, Baek SJ, Eling TE (2000) Lack of cyclooxygenase-2 activity in HT-29 human colorectal carcinoma cells. Exp Cell Res 256:563-570

29. Talmadge JE (2007) Pathways mediating the expansion and immunosuppressive activity of myeloid-derived suppressor cells and their relevance to cancer therapy. Clin Cancer Res 13:5243-5248

30. Namkoong S, Kim Y-M (2010) Therapeutic application of nitric oxide in human diseases. Biomol Ther 18:351-362

31. Oshikawa T, Okamoto M, Tano T, Ahmed SU, Sasai A, Kan S, Moriya Y, Ryoma Y, Saito M, Sato M (2006) Involvement of nitric oxide in anti-tumor effects of OK-432, a streptococcal anti-tumor immunotherapeutic agent. Int Immunopharmacol 6:764-773

32. Ma Q, Hoper M, Anderson N, Rowlands BJ (1996) Effect of supplemental L-arginine in a chemical-induced model of colorectal cancer. World J Surg 20:1087-1091

33. Ma Q, Wang Y, Gao X, Ma Z, Song Z (2007) L-arginine reduces cell proliferation and ornithine decarboxylase activity in patients with colorectal adenoma and adenocarcinoma. Clin Cancer Res 13:7407-7412

34. Clancy R, Varenika B, Huang W, Ballou L, Attur M, Amin AR, Abramson SB (2000) Nitric oxide synthase/COX cross-talk: nitric oxide activates COX-1 but inhibits COX-2-derived prostaglandin production. J Immunol 165:1582-1587

35. Ghosh DK, Misukonis MA, Reich Ch, Pisetsky DS, Weinberg JB (2001) Host response to infection: the role of CpG DNA in 
induction of cyclooxygenase 2 and nitric oxide synthase 2 in murine macrophages. Infect Immun 69:7703-7710

36. Cianchi F, Cortesini C, Fantappiè O, Messerini L, Sardi I, Lasagna N, Perna F, Fabbroni V, Di Felice A, Perigli G, Mazzanti R, Masini E (2004) Cyclooxygenase-2 activation mediates the proangiogenic effect of nitric oxide in colorectal cancer. Clin Cancer Res 10:2694-2704

37. Guastadisegni C, Nicolini A, Balduzzi M, Ajmone-Cat MA, Minghetti L (2002) Modulation of $\mathrm{PGE}_{2}$ and $\mathrm{TNF} \alpha$ by nitric oxide in resting and LPS-activated RAW 264.7 cells. Cytokine 19:175-180

38. Motta AB, Gonzales ET, Rudolph I, Gimeno MF (1999) Regulation of prostaglandin production by nitric oxide in rat smooth muscle myometrial cells. Prostaglandins Leukot Essent Fatty Acids 60:73-76

39. Novaro V, Rettori V, Gonzáles ET, Jawerbaum A, Faletti A, Canteros G, de Gimeno MAF (1996) Interaction between uterine $\mathrm{PGE}$ and $\mathrm{PGF}_{2 \alpha}$ production and the nitridergic system during embryonic implantation in the rat. Prostaglandins 51:363-376

40. Ohno R, Miyazawa T, Hayashi Y, Kanatsu K, Tanaka A, Takeuchi $\mathrm{K}$ (2002) Induction of intestinal damage by rofecoxib, the selective COX-2 inhibitor, under inhibition of nitric oxide production in rats. Immunopharmacology 10:435-447

41. Paoletti AM, Piccirilli S, Costa N, Rotiroti D, Bagetta G, Nisticò G (1998) Systemic administration of $\mathrm{N}^{\omega}$-nitro-Larginine methyl ester and indomethacin reduces the elevation of brain $\mathrm{PGE}_{2}$ content and prevents seizures and hippocampal damage evoked by $\mathrm{LiCl}$ and tacrine in rat. Exp Neurol 149:349-355
42. Yu L-B, Dong X-S, Sun W-Z, Zhao D-L, Yang Y (2005) Effect of a nitric oxide synthase inhibitor NG-nitro-L-arginine methyl ester on invasion of human colorectal cancer cell line SL-174T. World J Gastroenterol 11:6385-6388

43. West SD, Suliburk JW, Helmer KS, Mercer DW (2008) Cyclooxygenase-1 suppresses lipopolysaccharide-induced changes in rat gastric inducible nitric oxide synthase. Crit Care Med 36:572-579

44. Payá M, Pastor PG, Coloma J, Alcaraz MJ (1997) Nitric oxide synthase and cyclo-oxygenase pathways in the inflammatory response induced by zymosan in the rat air pouch. Br J Pharmacol 120:1445-1452

45. Nishikawa M, Stapleton P, Freeman TA, Gaughan JP, Matsuda T, Daly JM (2004) NS-398 inhibits tumor growth and liver metastasis of colon cancer through induction of apoptosis and suppression of the plasminogen activation system in a mouse model. J Am Coll Surg 199:428-435

46. Munkarah AR, Genhai Z, Morris R, Baker VV, Deppe G, Diamond MP, Saed GM (2003) Inhibition of paclitaxel-induced apoptosis by the specific COX-2 inhibitor, NS398, in epithelial ovarian cancer cells. Gynecol Oncol 88:429-433

47. Park S-W, Sung M-W, Heo D-S, Inoue H, Shim S-H, Kim K-H (2005) Nitric oxide upregulates the cyclooxygenase-2 expression through the camp-response element in its promoter in several cancer cell lines. Oncogene 24:6689-6698

48. Mollace V, Muscoli C, Masini E, Cuzzocrea S, Salvemini D (2005) Modulation of prostaglandin biosynthesis by nitric oxide and nitric oxide donors. Pharmacol Rev 57:217-252 